\title{
Bee pollen allergy in Polish beekeepers and their families
}

\author{
Katarzyna Basista, Barbara Filipek, Krystian Sodzawiczny
}

Department of Pharmacodynamics, Jagiellonian University, Medical College, Krakow, Poland Head: Prof. Barbara Filipek

Postep Derm Alergol 2012; XXIX, 5: 343-347

DOI: $10.5114 /$ pdia.2012.31486

\begin{abstract}
Introduction: A bee pollen allergy is rare and often confused with a pollen allergy. The possibility of inducing an allergy in pollen allergic patients by bee pollen is still controversial.

Aim: To determine the prevalence of bee pollen allergy in beekeepers and their families and its possible association with other conditions.

Material and methods: The questionnaire study was carried out on 493 Polish beekeepers. The questionnaire was based on the current literature and touched on several aspects of a bee products allergy.

Results: Only 19.4\% (493 from 2540 questionnaires sent) of questionnaires were returned by 15 October 2011. From the total group, only 2 beekeepers reported adverse reactions after bee pollen ingestion. They presented only minor reactions. From 493 beekeepers, 43 responders reported other allergies. From that group, no one reported a concomitant bee pollen allergy. Additionally, beekeepers reported only 22 cases of bee pollen intolerance among their customers and in family members a bee pollen allergy occurred in $0.56 \%$ of cases.

Conclusions: This preliminary study provides some new aspects on the bee pollen allergy. The thesis that a bee pollen allergy is associated with the occurrence of proteins from bee saliva rather than the occurrence of anemophilous plant pollen should be evaluated in future studies.
\end{abstract}

Key words: bee pollen allergy, beekeepers, bee products allergy, occupational allergy.

\section{Introduction}

Pollen contains microgametophytes which produce the male gametes of seed plants for the pollination process. In anemophilous plants, pollen is transferred by wind. In entomophilous plants, pollen is transferred by insects, mainly bees. Pollen collected by bees is called bee pollen. It should be distinguished from pollen from anemophilous plants because it has different properties, mainly in inducing allergy [1, 2].

Pollen from anemophilous plants often causes an allergy called pollinosis. This illness is induced by glycoprotein derivatives which are located in the external part of the pollen cell wall. Pollen from anemophilous plants is carried by wind and it is delivered through the air to the mucous membrane of the nasal cavity and eyeball. Such pollen can induce allergic reactions and allergens responsible for this situation are glycoproteins mentioned above. Such compounds bond to receptors situated in mucous membranes, they stimulate secretion of histamine and in effect they cause inflammation [3-5].
However, entomophilous pollen is a different case. Pollen cells are considerably larger and in the majority they are not covered with allergic compounds. Bees are the most important group of insects in plant pollination. Bees eat pollen, which constitutes the most important protein-rich food. Bees collect nectar in special scopa on their hind legs and they gather pollen and conglomerate it with saliva and nectar. It is made into a special coherent mass of pollen grains called pollinium. Bees fly over a lot of plants carrying pollen and in this way they pollinate plants. However, their main aim is to collect and gather food. Bee pollen is stored in honeycombs. Bees beat down pollen and during the final stage they introduce enzymes and Lactobacillus bacteria from their alimentary canal. Lactobacillus bacteria reduce proteins and polysaccharides to simpler compounds and they take part in the fermentation process of pollen. Finally, fermenting pollen is soaked with nectar and, by doing this, bee bread, the most important bee food, is made [6-8].

Bees conglomerate pollen, as it was said earlier, using their saliva which is rich in enzymes. It is absolutely essen-

Address for correspondence: Katarzyna M. Basista, Department of Pharmacodynamics, Jagiellonian University, Medical College, 9 Medyczna St, 30-688 Krakow, Poland, phone: +48 508932 783, e-mail: katarzyna.basista@gmail.com 
tial because the enzymes induce the reduction of glycosidic bonds in glycoproteins on pollen cells of anemophilous plants, which is sometimes gathered by bees in scopa. In effect, even if bees collect pollen covered with allergic glycoproteins from anemophilous plants, glycoproteins will hydrolyze and deactivate [2].

\section{Material and methods}

In the Pharmacodynamic Department in the Faculty of Pharmacy at the Jagiellonian University, a questionnaire study of allergy to bee products in a group at high risk such as beekeepers and their families, is now being conducted.

\section{Study questionnaires}

The questionnaire 'Allergy to propolis among beekeepers' was developed on the basis of earlier investigations on the subject of allergy and on reports of various disorders in beekeepers, on the allergy to bee products in the general population and on questionnaire research in other fields of medicine. The questionnaire was tested on 20 volunteers for intelligibility. A copy of the questionnaire is available from $\mathrm{KB}$.

\section{Subjects}

Questionnaires are delivered to beekeepers by hand through the Beekeepers Association, especially the Provincial Association of Apiarists in Krakow. This study is direct-

Table 1. Demographic characteristics of the studied beekeeper group

\begin{tabular}{ll}
\hline Characteristic & Result \\
\hline Age [years]: & \\
\hline$\leq 20$ & $0.40 \%$ \\
\hline $21-40$ & $12.58 \%$ \\
\hline $41-60$ & $45.84 \%$ \\
\hline$>60$ & $41.18 \%$ \\
\hline Gender: & $6.29 \%$ \\
\hline Female & $93.71 \%$ \\
\hline Male & \\
\hline Time spent as a beekeeper [years]: & $6.90 \%$ \\
\hline$\leq 5$ & $15.01 \%$ \\
\hline $6-10$ & $15.01 \%$ \\
\hline $11-15$ & $63.08 \%$ \\
\hline$>15$ & \\
\hline Number of bee hives in the farm: & 42.69 \\
\hline Median & \\
\hline Range & \\
\hline
\end{tabular}

ed at beekeepers who are an occupational group being the most affected by propolis contact allergy and bee products allergy. The study is conducted on adults of both genders after obtaining informed consent to participate in the study. Every beekeeper who gave informed consent was included in the study.

\section{Statistical analysis}

The Statistica program licensed by the Faculty of Pharmacy of the Jagiellonian University Medical College in Krakow was used for data management and statistical analysis.

\section{Ethical approval}

The study was submitted to the Bioethics Committee of the Jagiellonian University in Krakow, Poland. The agreement was approved on 25th November 2010 (number of agreement KBET/211/B/2010).

\section{Results}

A total number of 2540 questionnaires were sent, including 1360 questionnaires in the Malopolska region. By 15 October 2011, 493 questionnaires were returned, including 345 from the Malopolska region. The percentage of response was $19.4 \%$ (24.5\% - Malopolska region), which shows a small interest among beekeepers in occupational allergies and a little agreement between beekeepers and researchers. The characteristics of the responding beekeepers are given in Table 1 .

Preliminary results show that the bee pollen allergy in beekeepers is extremely rare $(0.41 \%)$. Only 2 beekeepers (from 493 Polish beekeepers) report side-effects after bee pollen ingestion. These are only minor reactions. One case describes abdominal pain and the other - a local rash. From 493 beekeepers, only 11 (2.23\%) report on allergy to bee products other than propolis: 2 beekeepers are allergic to bee pollen, 2 are allergic to honey and 7 beekeepers are allergic to bee venom. The results of the study of bee products allergy excluding propolis are shown in Table 2.

From 493 beekeepers, 43 (8.72\%) of them report allergies other than bee products allergies. Among them there are no bee pollen allergic individuals. The majority of bee-

Table 2. Allergy to bee products excluding propolis among Polish beekeepers

\begin{tabular}{lcc}
\hline Bee products & $\begin{array}{c}\text { Number of allergic } \\
\text { beekeepers }\end{array}$ & $\begin{array}{c}\text { Allergic beekeepers [\%] } \\
(n=493)\end{array}$ \\
\hline Bee pollen & 2 & 0.002 \\
\hline Honey & 2 & 0.002 \\
\hline Royal jelly & 0 & 0 \\
\hline Bee venom & 7 & 1.42 \\
\hline
\end{tabular}


keepers (272 people, 55.2\%) have very good or good experience with bee pollen. About 172 patients (34.9\%) report a lack of experience, while only 14 patients (2.8\%) report bad experience with bee pollen. Thirty-five patients (7.1\%) have neither bad nor good experiences. The results of the study of beekeepers' experience of the healthy value of bee pollen are shown in Table 3. In spite of different bee pollen experiences as many as 393 beekeepers (79.7\%) recommend bee pollen to their customers. It is evident from this study that even some beekeepers who say that they have no experience with bee pollen would recommend bee pollen to their customers. Maybe this question was not comprehensible or in fact beekeepers sell bee pollen without justified conviction about its properties.

Obtained data from beekeepers made it possible to estimate the number of cases of a bee pollen allergy in customers and among members of their families, who consumed bee pollen. Beekeepers reported 22 cases among customers of allergy or intolerance to bee pollen (mainly gastrointestinal side effects). Among members of beekeepers' families, bee pollen allergy occurs only in 0.56\% (8 allergic patients from total 1414 individuals). Symptoms of bee pollen allergy include itching and rashes, but no serious cases of allergy intensification are reported. It was sufficient to stop taking bee pollen and the symptoms disappeared spontaneously. Three cases out of eight suffered from different types of allergy previously. In the other five cases, no different allergies were confirmed.

The above data are the first such data published and they are preliminary results. Although the study did not finish, the preliminary results about severity and the scale of bee pollen allergy can be announced.

\section{Discussion}

This study confirms that a bee pollen allergy is extremely rare, though it can occur in people allergic or not to pollen of plants. Obviously, if people are allergic to bee products, for example honey, they should be cautious about using bee pollen. Nevertheless, allergic reactions after bee pollen ingestion are not intensified. It should be mentioned that among bee products allergic subjects, including bee pollen allergic people, nobody was allergic to two or more bee products, what can suggest a lack of cross-reactivity between bee products.

In the world literature, 10 cases of allergic reaction after bee pollen ingestion have been described. Taking into consideration the number of people using bee pollen, only 10 cases of side effects in the world is not a demonstrative number. Moreover, this scale of the phenomenon does not show a general risk related to bee pollen ingestion, even for people with pollinosis [9-15].

It needs to be discussed whether bee pollen allergy is related with the occurrence of proteins from insect saliva or from anemophilous pollen derivatives. The state-
Table 3. Beekeepers' experience of the healthy value of bee pollen

\begin{tabular}{lcc}
\hline $\begin{array}{l}\text { Experience of the healthy } \\
\text { value of bee pollen }\end{array}$ & $\begin{array}{c}\text { Number } \\
\text { of people }\end{array}$ & $\begin{array}{c}\text { Percentage } \\
\text { of people }\end{array}$ \\
\hline Lack of experience & 172 & 34.9 \\
\hline Very bad experience & 0 & 0 \\
\hline Bad experience & 14 & 2.8 \\
\hline Neither good nor bad experience & 35 & 7.1 \\
\hline Good experience & 106 & 21.5 \\
\hline Very good experience & 166 & 33.7 \\
\hline
\end{tabular}

ment that the bee pollen allergy is related with proteins from bee pollen saliva was partly confirmed by researchers in the 1980-ties from the Pharmaceutical Botany Department in the Pharmaceutical Faculty in Krakow in cooperation with the Apiarian Company Apipol and with the medicinal plants planters from Pinczow. Unfortunately, at that time this study was not described, but it was carried out by the co-author of this article and because of that this study will be briefly described here.

At the plantation of ribwort (Plantago lanceolata) which pollen is a well-known allergen, hives with pollen traps were spaced out. Bees were fed with the sugar syrup and the only source of pollen was ribwort plantation. Bees collected pollen mainly from that plant. In collected pollen, researchers identified more than $90 \%$ of ribwort pollen. Then, bee pollen gathered from bees was planned to be administered to patients to induce an allergic reaction. After this experiment, the new anti-allergic autovaccine was supposed to be designed. Unfortunately, it turns out that in the bee pollen extract no ribwort allergens were present. This experiment suggests that bee pollen cannot be related to inducing allergy in people allergic to anemophilous pollen. Maybe it induces allergy very rarely, but rather in bee products allergic patients related with the presence of bee saliva proteins. However, a further full study should be conducted to establish this.

Authors of this article do not claim that bee pollen does not induce allergy. It is sure that the allergy to bee pollen is not severe and it is not a great risk to the general population. It does not seem that for people allergic to pollen of anemophilous plants, bee pollen ingestion can be harmful. It seems that bee pollen consumption in such groups of allergic people does not carry a significant risk, which can also result from studies cited below.

Schäfer and Przybilla took blood samples of 258 people (children and adults). They measured Hymenoptera venom specific serum IgE antibodies and they investigated a history of atopic disease or systemic anaphylactic reaction to Hymenoptera stings. In $24.8 \%$ of cases, specific IgE antibodies to Hymenoptera venom and in $8.5 \%$ - specific IgE antibodies to wasp venom were found. Only 9 individuals (3.3\%) out of the total studied group report- 
ed a systemic anaphylactic reaction to insect stings. Among people with specific lgE antibodies to insect stings (86 patients) only 6 subjects reported systemic allergic reactions. From the studied population, $16.7 \%$ of subjects had a history of an atopic disease (asthma, atopic eczema, hay fever). However, specific IgE antibodies to 4 common aeroallergens (grass pollen, birch pollen, house-dust mite, cat dander) were found in the serum of $32.6 \%$ of patients. Authors concluded that specific serum IgE antibodies to Hymenoptera venom is significantly associated with specific IgE antibodies to 3 of the 4 aeroallergens (grass pollen, birch pollen, house-dust mite). Immunologic sensitization to Hymenoptera venom is common in the general population and is associated with atopy-related humoral IgE hyperresponsiveness [16].

Kochuyt et al. investigated the relationship between misdiagnosis of multivalent pollen sensitization in bee venom allergic patients. Bee stings can induce the synthesis of specific IgE antibodies to carbohydrate determinants on bee venom allergens glycoproteins, that crossreact with carbohydrate determinants in pollen. Such cross-reactions are believed to have little or no biological activity and therefore they may be the reason of misdiagnosis in relation to pollen sensitization after a sting. Authors showed that the risk of misdiagnosis in Hymenoptera venom allergic patients is about 16\%. Moreover, the researchers showed that the sting induced anti-pollen slgE expression, which have similar carbohydrate determinants in venom and in pollen. The recognition of crossreacting carbohydrate determinants might be associated with the atopic feature [17].

Pitsios et al. examined 202 people, fifty seven of which were nonatopic control subjects and 145 were atopic patients with respiratory allergies and with symptoms of rhinitis and rhinoconjunctivitis and/or asthma. All patients underwent skin prick tests with bee pollen extracts. None of the control group subjects demonstrated positive skin prick tests to bee pollen extracts. However, $73 \%$ of atopic patients reacted to one or more bee pollen extracts in skin prick tests. Authors claimed that bee pollen contains a certain quantity of airborne pollen and that can indicate a potential risk of inducing allergic reactions in atopic patients after ingesting bee pollen. Taking into consideration studies of Schäfer and Przybilla [16] and Kochuyt et al. [17] it is worth noticing that the result of $73 \%$ in the atopic population seems to be untrue. According to us, this study is not fully reliable. It should be checked whether those atopic patients are not allergic to bee venom and whether this allergy is not the reason of misdiagnosis [18].

\section{Conclusions}

The bee pollen allergy and a potential risk for patients with pollinosis remains an unsolved question. It seems that some investigations in which authors prove the risk of bee pollen ingestion in patients allergic to anemophilous pollen are not fully reliable. Taking into consideration the broad consumption of bee pollen, even with honey, as well as the frequency of pollinosis (about 20\%) in the general population it does not seem that 10 cases of allergic reactions after bee pollen ingestion described in the world literature are the reason to prevent bee pollen ingestion among allergic patients. According to us, bee pollen allergy is associated with the occurrence of proteins from insect saliva. However, taking into consideration not many studies in that matter, further studies are needed to evaluate this thesis and the safety of ingesting bee pollen by airborne pollen allergic patients.

\section{Acknowledgments}

We would like to thank beekeepers, who participated in this study and the Beekeepers Association, especially the Provincial Association of Apiarists in Krakow for their help with this study.

\section{References}

1. Kedzia B, Holderna-Kedzia E. Bee products in medicine [Polish]. Wydawnictwo Spoldzielnia Pszczelarska „Apis”, Lublin.

2. Tichonow Al, Sodzawiczny K, Tichonow SA, et al. Bee pollen - pollen ball in pharmacy and medicine [Polish]. Apipol- Farma, Krakow 2008.

3. Gliński W, Rudzki E. Allergology for doctors and allergists [Polish]. Czelej, Lublin 2002.

4. Grevers G, Röcken M. Illustrated manual of allergic diseases. Elsevier, 2002.

5. Heldal KK, Mads $\varnothing$ L, Huser PO, Eduard W. Exposure, symptoms and airway inflammation among sewage workers. Ann Agric Environ Med 2010; 17: 263-8.

6. Ellnain-Wojtaszek M. Bee products-valuable medicines from natural medicine [Polish]. Gospodarstwo Pasieczne „Sądecki Bartnik", Nowy Sącz 1998.

7. Kędzia B, Hołderna-Kędzia E. Bee products in the therapy, the issues selected [Polish]. Fundacja Humana Divinis, Torun.

8. Poprawko SA. How do bees protect them selves and their products [Polish]. Państwowe Wydawnictwo Rolnicze i Leśne, Warszawa 1989.

9. Greenberger PA, Flais MJ. Bee pollen-induced anaphylactic reaction in an unknowingly sensitized subject. Ann Allergy Asthma Immunol 2001; 86: 239-42.

10. Puente S, Iñiguez A, Subirats M, et al. Eosinophilic gastroenteritis caused by bee pollen sensitization. Med Clin (Barc) 1997; 108: 698-700.

11. Lin FL, Vaughan TR, Vandewalker ML, Weber RW. Hypereosinophilia, neurologic, and gastrointestinal symptoms after bee-pollen ingestion. J Allergy Clin Immunol 1989; 83: 793-6.

12. Mansfield LE, Goldstein GB. Anaphylactic reaction after ingestion of local bee pollen. Ann Allergy 1981; 47: 154-6.

13. Martín-Muñoz MF, Bartolome B, Caminoa M, Bobolea I. Bee pollen: a dangerous food for allergic children. Identification of responsible allergens. Allergol Immunopathol (Madr) 2010; 38: 263-5.

14. Prichard M, Turner KJ. Acute hypersensitivity to ingested processed pollen. Aust N Z J Med 1985; 15: 346-47. 
15. Stankiewicz-Choroszucha BL, Wawrzyniak ZM, Lipiec A, et al. Consequences of smoke inhalation in the "Epidemiology of Allergic Diseases in Poland' project (ECAP). Ann Agric Environ Med 2011; 18: 420-8.

16. Schäfer T, Przybilla B. IgE antibodies to Hymenoptera venoms in the serum are common in the general population and are related to indications of atopy. Allergy 1996; 51: 372-7.

17. Kochuyt AM, Van Hoeyveld EM, Stevens EA. Prevalence and clinical relevance of specific immunoglobulin $E$ to pollen caused by sting-induced specific immunoglobulin E to cross-reacting carbohydrate determinants in Hymenoptera venoms. Clin Exp Allergy 2005; 35: 441-7.

18. Pitsios C, Chliva C, Mikos N, Kompoti E. Bee pollen sensitivity in airborne pollen allergic individuals. Ann Allergy Asthma Immunol 2006; 97: 703-6. 